\title{
Foetal and Perinatal Autopsy - A Study Of 100 Cases
}

\author{
Sharanabasav M Choukimath*, Sujata S Giriyan and Priyadharshini Bargunam \\ Department of Pathology, Karnataka Institute of Medical Sciences, Hubballi, Karnataka, India
}

\begin{abstract}
Background: Perinatal and foetal Autopsy pave way for bringing down these preventable stillbirths by identifying the potential areas where the health system tend to fail and helps to rule out congenital and infectious diseases and hence their recurrence.
\end{abstract}

Aims: 1 . To describe and analyse the foetal and perinatal death.

2. To determine how often the perinatal autopsy determines and confirms the cause of death and how often it changes the clinical diagnosis.

Methods and Material: Autopsy was performed by the pathologist after obtaining informed written consent from parents, examining grossly and microscopically. The cause of death, whenever found was classified according to the ReCoDe system of classification of cause of death.

Results: Cause of death was found in 101 (96.2\%), unknown in 4 cases (3.8\%). Foetal causes were found in 55 (52.4\%), lethal Congenital Malformation was seen in $31(29.5 \%)$ cases. Maternal causes were seen in $21(20 \%)$, placental causes were seen in $11(10.5 \%)$ cases. Other causes were attributed in $14(13.3 \%)$ cases.

Autopsy added significant findings to the prenatal diagnosis in 10 cases (10\%) and changed and added new findings in ( $9 \%) 9$ cases. While in $(81 \%) 81$ cases, it had confirmed the clinical diagnosis.

Conclusions: Despite technological advancements, foetal autopsy remains gold standard for diagnosing the cause of death of foetus thus helping prenatal counselling

Keywords: Foetal Autopsy, Perinatal Autopsy,ReCoDe

\section{Introduction}

With more than 3 million perinatal deaths occurring each year worldwide, ${ }^{[1]}$ ending preventable stillbirths and neonatal deaths is a challenge for a developing country like India which has a perinatal mortality rate of 26 per 1000 live births. With major objectives of determining the gestational age, documenting growth and development, detecting congenital abnormalities, analysing clinical diagnosis and treatment and determine the cause of death and possible recurrence risk, ${ }^{[2]}$ perinatal and foetal Autopsy pave way for bringing down these preventable stillbirths by identifying the potential areas where the health system tend to fail and helps to rule out congenital and infectious diseases and hence their recurrence. Although prenatal diagnostic procedures provide confirmation regarding the presence of a foetal anomaly, autopsy remains an important contributor to the final diagnostic classification and subsequent counselling. ${ }^{[3,4,5]}$ Even in the current era of MRI Autopsy, it remains gold standard and helps to confirm, change or add to the clinical diagnosis. ${ }^{[6]}$

\section{Material and Methods}

This is a prospective, Cross sectional study done from September 2017 to June 2018, done to describe and analyse the foetal and perinatal death and determine how often the perinatal autopsy determines the cause of death. Consecutive 100 autopsy cases received in our department of Pathology were studied. This study includes the perinatal death as per the latest WHO definition i.e. the death of a foetus from period commencing from 22 completed weeks of gestational age (the time when birth weight is usually 500 grams) or the death of an infant between birth and at the end of the early neonatal period (1- 7 days), according to WHO and Foetal death (death prior to the complete expulsion or extraction from mother, irrespective of the duration of pregnancy, excluding termination of pregnancy, according to the 2003 revision of the Procedures for Coding Cause of Foetal Death Under ICD-10.

Autopsy examination of the foetus or neonate was performed after obtaining informed written consent from parents or the guardian explaining the procedure and the utility of the outcome. All autopsies were performed by the pathologist. Each foetus was examined according to a predetermined protocol which included clinical and ultrasound diagnosis, photographs, Multiple X rays, anthropometry, external and internal examination. The thoracic, cervical, abdominal and pelvic organs were removed en bloc and subsequently 
dissected into organ blocks. Sections were given from Brain, heart, thymus, lungs, liver, spleen, kidneys, adrenal, colon, muscle \& placenta, umbilical cord and membranes. Antenatal ultra-sonogram findings were correlated with the autopsy findings. The cause of death, whenever found was classified according to the ReCoDe system ${ }^{[7,8]}$ as the WHO classification is still under trial. ${ }^{[9]}$ After diagnosing, the organ blocs and the bodies were disposed according to the latest biomedical waste management protocols.

\section{Results}

Consecutive 100 perinatal and foetal autopsies were included in the study which comprised 8 twins, hence a total of 105 autopsies were included [As in 3 twin cases, one of the twins survived]. It included 14 term (37- 40 weeks), 8 late preterm (34- 36 6/7 weeks), 61 early preterm (22- 33 6/7 weeks) babies and 14 foetuses (< 12 weeks). Cause of death was found in $101(96.2 \%)$, unknown in 4 cases $(3.8 \%)$.

Amongst the 101 cases, foetal causes were found in 55 $(52.4 \%)$, maternal causes were seen in $21(20 \%)$, placental causes were seen in $11(10.5 \%)$ cases. Other causes were attributed in $14(13.3 \%)$ cases. Lethal Congenital Malformations were seen in 31 (29.5\%) cases with Male: Female ratio of 1: 1.5, of which CNS malformations were the most common. Table 1 describes the various congenital malformations seen in this study, highlighting the cases in which autopsy changed the cause of death. Other foetal causes were fetal growth restriction in 9 cases $(8.5 \%)$, fetal infections in 8 cases $(7.61 \%)$, twin to twin transfusion syndrome in 6 cases $(5.7 \%)$ and foetal isoimmunisation in $1(0.95 \%)$ case. Table 2 shows gestational age wise classification of cause of death according to ReCoDe classification of cause of death.

Autopsy added significant findings to the prenatal diagnosis in 10 cases $(10 \%)$ and changed and added new findings which helped to categorise them under a syndrome hence aiding in prenatal genetic counselling in (9\%) 9 cases. While in rest of the cases (81\%) 81 cases, it had confirmed the clinical diagnosis, hence reinstating the utility of foetal autopsies even in this era of modern technologies.

Table 1: Distribution of Congenital Anomalies in the study. * Cases in which Autopsy added significant findings, changing or contributing to the diagnosis. IUGR- Intrauterine growth Retardation. BL- bilateral.

\begin{tabular}{|c|c|c|c|}
\hline \multicolumn{2}{|r|}{ CONGENITAL ANOMALIES } & ASSOCIATED FEATURES & NO $(n=31)$ \\
\hline \multicolumn{4}{|c|}{ I. CENTRAL NERVOUS SYSTEM ANOMALIES n= 17 (54.9\%) } \\
\hline 1 & Occipital meningomyelocele & Cystic Hygroma & 1 \\
\hline 2 & $\begin{array}{l}\text { Obstructive Hydrocephalus, Arnold Chiari Malformation, } \\
\text { Thoracolumbar meningomyelocele }\end{array}$ & Club foot, Depressed nasal bridge, IUGR & 1 \\
\hline 3 & Anencephaly & IUGR & 2 \\
\hline 4 & Spina bifida, Meningomyelocele* & $\begin{array}{l}\text { Club foot, Cleft lip \& Cleft palate, Focal } \\
\text { Calcification of Brain, IUGR }\end{array}$ & 1 \\
\hline 5 & Sacral Meningomyelocele, Spina Bifida & IUGR & 2 \\
\hline 6 & Anencephaly* & $\begin{array}{l}\text { IUGR, web neck, low set ears, Increased } \\
\text { Intercanthal distance }\end{array}$ & 1 \\
\hline 7 & Exencephaly & IUGR & 1 \\
\hline 8 & Encephalocele & & 1 \\
\hline 9 & Arnold chiari malformation, hydrocephalus & Cystic hygroma & 2 \\
\hline 10 & Mild Hydrocephalus, Hemimegalencephaly & IUGR & 1 \\
\hline 11 & Hydrocephalus* & $\begin{array}{l}\text { Fused \& hypoplastic } 4 \text { th } \& 5 \text { th toe, Single } \\
\text { Umbilical Artery }\end{array}$ & 1 \\
\hline 12 & Hydrocephalus & Absent nasal bone, Short long bones & 1 \\
\hline 13 & Hydrocephalus, Lumbar Spina Bifida, Meningocele & IUGR & 1 \\
\hline
\end{tabular}




\begin{tabular}{|c|c|c|c|}
\hline \multicolumn{2}{|r|}{ CONGENITAL ANOMALIES } & ASSOCIATED FEATURES & NO $(n=31)$ \\
\hline \multicolumn{4}{|c|}{ II. CARDIOVASCULAR ANOMALIES n= 4 (12.9\%) } \\
\hline 1 & Left Heart Hypoplasia & IUGR & 1 \\
\hline 2 & Complex Cardiac Anomaly & Single Umbilical Artery, Foetal Ascitis & 1 \\
\hline 3 & Pre ductal Coarctation Of Aorta* & IUGR & 1 \\
\hline 4 & Dilated RV, Hypoplastic LV, PA Stenosis & IUGR & 1 \\
\hline \multicolumn{4}{|c|}{ III. SYNDROMES/ SEQUENCES n= $3(9.7 \%)$} \\
\hline 1 & Twin Reversed Arterial Perfusion Sequence (TRAPS)* & $\begin{array}{l}\text { Absent BL Lungs, Liver, heart, Single } \\
\text { Umbilical Artery }\end{array}$ & 1 \\
\hline 2 & Pena Shokeir Syndrome* & $\begin{array}{l}\text { Multiple Arthrogryposis congenital, } \\
\text { Micrognathia, Bifid uvula }\end{array}$ & 1 \\
\hline 3 & $\begin{array}{l}\text { Ivemark Syndrome- Asplenia with Right Isomerism, } \\
\text { Endocardial cushion defects* }\end{array}$ & BL Trilobular Lungs, Asplenia, ASD, VSD & 1 \\
\hline \multicolumn{4}{|c|}{ IV. MUSCULOSKELETAL ANOMALIES n= 2 (6.5\%) } \\
\hline 1 & Micrognathia, Absent thumb, prominent occiput & club foot, Bilateral Short arm & 1 \\
\hline 2 & Micromelia & IUGR & 1 \\
\hline \multicolumn{4}{|c|}{ V. GENITOURINARY ANOMALIES n= $2(6.5 \%)$} \\
\hline 1 & Bilateral Renal Agenesis \& Hypoplasia & Chorioamnionitis, IUGR & 2 \\
\hline \multicolumn{4}{|c|}{ VI. ABDOMINAL ANOMALIES n= 1 (3.2\%) } \\
\hline 1 & Omphalocele & IUGR & 1 \\
\hline \multicolumn{4}{|c|}{ VII. MULTIPLE MALFORMATIONS n= 2 (6.5\%) } \\
\hline 1 & $\begin{array}{l}\text { Cystic Adenomatoid Malformation Lung, Cystic Renal } \\
\text { Dysplasia* }\end{array}$ & Malformed limbs & 1 \\
\hline 2 & Severe Micromelia* & Hypoplastic lungs, Jejunoileal atresia, IUGR & 1 \\
\hline
\end{tabular}

Table 2: Gestational age wise classification of cause of death by ReCoDe Classification.

\begin{tabular}{|c|c|c|c|c|c|c|c|c|c|c|}
\hline \multirow{2}{*}{\multicolumn{2}{|c|}{ Amniotic fluid }} & \multicolumn{8}{|c|}{ ReCoDe- Classification of cause of death } & \multirow[b]{2}{*}{ Total } \\
\hline & & Foetal & Intrapartum & Maternal & Placental & Trauma & Umbilical & Un- & & \\
\hline \multirow{4}{*}{$\begin{array}{c}\text { GESTATIONAL } \\
\text { AGE }\end{array}$} & EARLY PRETERM & 1 & 29 & 3 & 17 & 7 & 2 & 2 & 2 & $63(60 \%)$ \\
\hline & FOETUS & 0 & 13 & 0 & 0 & 2 & 0 & 0 & 2 & $\begin{array}{c}17 \\
(16.2 \%)\end{array}$ \\
\hline & LATE PRETERM & 0 & 5 & 2 & 3 & 1 & 0 & 0 & 0 & $\begin{array}{c}11 \\
(10.5 \%)\end{array}$ \\
\hline & TERM & 0 & 8 & 4 & 1 & 1 & 0 & 0 & 0 & $\begin{array}{c}14 \\
(13.3 \%)\end{array}$ \\
\hline \multicolumn{2}{|c|}{ Total } & $1(0.95 \%)$ & $55(52.4 \%)$ & $9(8.6 \%)$ & $21(20 \%)$ & $11(10.5 \%)$ & $2(1.9 \%)$ & $2(1.9 \%)$ & $4(3.8 \%)$ & 105 \\
\hline
\end{tabular}



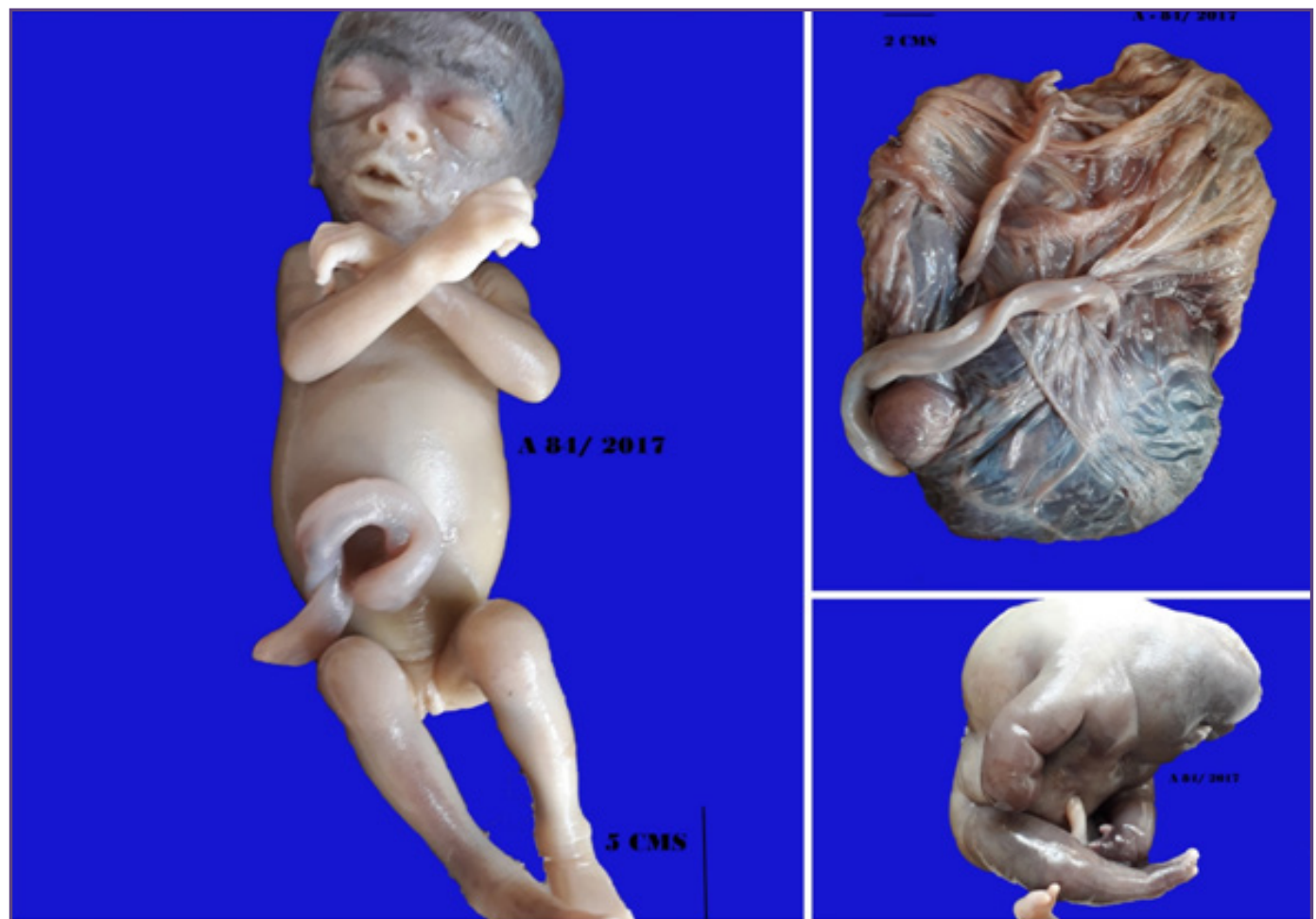

FIG. 1: Twin Reverse Arterial Perfusion (TRAP) Syndrome. (Clockwise) Pump twin, Fused Monochorionic Diamniotic placenta with the umbilical cord of TRAP twin being hypoplastic and AcephalicAcardiac (TRAP) twin.
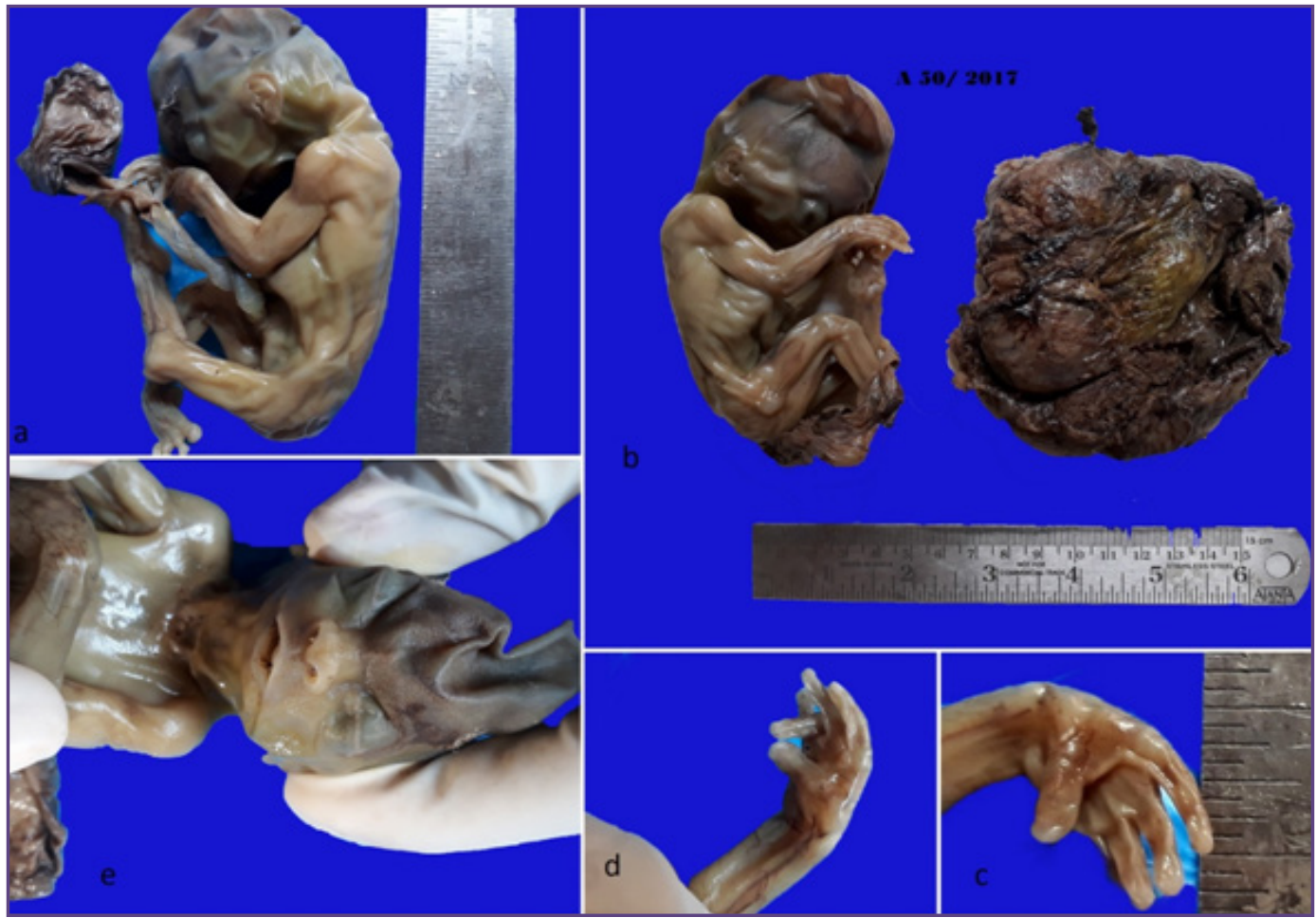

FIG. 2: Pena Shokeir syndrome- Arthrogryposis multiplex congenita with micrognathia a) Left lateral view showing extended left knee and generalised muscle wasting b) Right lateral view - with flexed right hip and knee joints and internally rotated ankle joint c) Ulnar deviation of wrist joint with thumb in palm appearance d) flexed fingers e) micrognathia. 


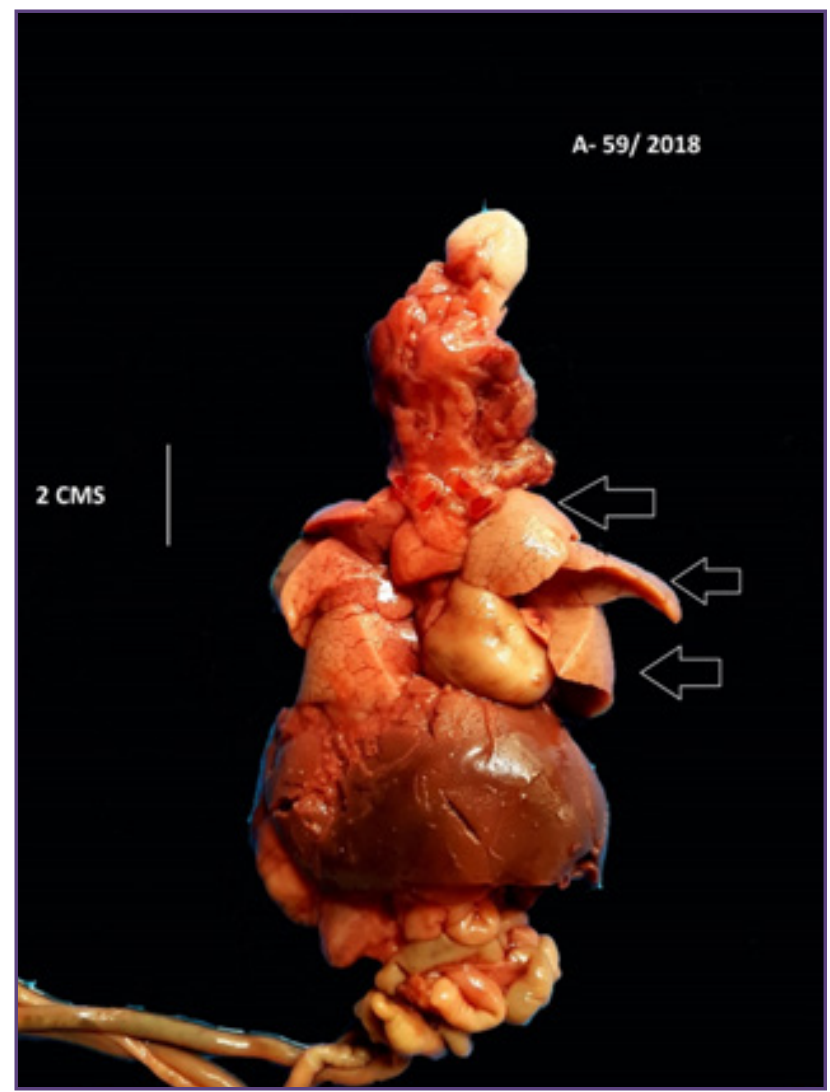

FIG. 3: Ivemark Syndrome (Right heterotaxy)- En bloc showing left sided trilobed lungs, central liver, absent spleen and malrotated gut.

\section{Discussion}

Foetal or perinatal death leads to a significant negative psychological impact on the mother and the entire family. The future reproductive decision of the couple depends on the cause of the foetal loss provided by the autopsy, which will predict the recurrence risk and may provide options for prevention of similar mishap. ${ }^{[10]}$

Saller et al ${ }^{[6]}$ have analysed 124 cases of perinatal deaths to assess the clinical utility of autopsy and were able to find the cause in $75.8 \%$ of all perinatal deaths and $62.3 \%$ of foetal deaths. In our study the cause of death was found in 101 cases $(96.2 \%)$ out of 105 cases. In 4 cases $(3.8 \%)$, cause of death was unknown. In 78 cases $(74.3 \%)$, cause of death could be concluded just with autopsy, but in 23 cases $(21.9 \%)$ the aid of clinical and imaging findings was mandatory to conclude the diagnosis.

In this study most of the deaths were attributed to be of fetal origin in 55 cases $(52.4 \%)$, of which lethal congenital malformations were seen in 31 cases $(29.52 \%)$. This is in correlation with the study of 134 neonatal autopsies by Joshi VV et al, ${ }^{[11]}$ where the congenital malformations contributed to $10.5 \%$ of the cases, though the study was done exclusively on neonates. Pradhan R et al, ${ }^{[12]}$ attributed $70 \%$ cause of perinatal death due to congenital deformity, probably because a malformed fetuses are consented frequently for autopsies.

Among the congenital malformations, central nervous system malformations were the most common, seen in 17 (54.9\% of congenital malformations) cases. This is comparable with findings of Kaiser et al, ${ }^{[13]}$ where CNS malformations were seen in $45(37 \%)$ cases, Grover $\mathrm{N}$ et al, ${ }^{[14]}$ seen in $72(40 \%)$ cases and Tomatir ${ }^{[15]}$ et al seen in 57 cases $(31.1 \%)$.

Single umbilical artery was seen in 5 cases $(4.8 \%)$ in our study, but was prenatally diagnosed only in $2(1.9 \%)$ cases. Three of these cases were associated with lethal congenital anomalies; one was associated with uteroplacental insufficiency and the other with velamentous insertion of umbilical cord. The identification of a Single Umbilical Artery in a twin pregnancy should prompt a very careful search for a foetal anomaly on ultrasound. Aneuploidy should be considered, particularly in the presence of a foetal anomaly. ${ }^{[16]}$ Associated anomalies may be found with a SUA in up to $30 \%$ of cases in both twin and singleton pregnancies, though incidence is higher in Twin pregnancies.

Twin reversed arterial perfusion sequence (TRAP) resulting in an acardiac twin occurs in 1:34,600 births or 1\% of all monozygotic twins, ${ }^{[17]}$ where the normal twin 'pumps' or 'donates' blood to the abnormal twin, which is called the 'recipient' or 'perfused' twin through abnormal arteryto-artery or venous-to-venous communications in the placenta. ${ }^{[18]}$ In our case, the recipient twin had malformed upper trunk with absent facial structures, anophthalmia, absent ears and mouth (Figure- 1). Internal examination showed absent bilateral lungs, heart, and liver. It was associated with single umbilical artery, as seen in $75 \%$ of these cases and the umbilical cord diameter was small compared to the donor umbilical cord. Vascular disruptions early in pregnancy are known to cause reabsorption of the tissues affected, resulting in complete absence or atresia of organs. ${ }^{[19]}$ Recurrence of TRAP syndrome is unknown/not increased, likely to be low and the couples can therefore be counselled optimistically for future pregnancy. ${ }^{[20]}$

Pena Shokeir syndrome is a rare, early lethal disorder with an estimated incidence of 1:12,000. Approximately one hundred cases have been reported so far. ${ }^{[21]}$ Though in some families, a recessive autosomal inheritance has been described with frame shift mutation in the RAPSN gene, and homozygous truncating mutation in the DOK7 gene, ${ }^{[22]}$ it is proposed that this condition is rather a description 
of a clinically and genetically heterogeneous phenotype from variable aetiology, resulting from the reduction of movements in the uterus due to an intrinsic pathology regardless of the cause, and was subsequently included among the phenotypes associated with the foetal akinesia/ hypokinesia deformation sequence (FADS). ${ }^{[23]}$ In our case, mother had uterine synechiae restricting the movement of the foetus. Hence provisionally it was diagnosed as environment induced arthrogryposis multiplex congenital. But foetus had micrognathia with bifid uvula and pulmonary hypoplasia suggesting the presence of Pena Schokeir syndrome which is described to have autosomal recessive inheritance (Figure- 2).

Ivemark syndrome is a heterotaxy syndrome affecting multiple organs of the body, often presenting with congenital asplenia and cardiac problems, [24] with estimated incidence of 1 in 5000 to 7000 live births. ${ }^{[25]}$ A single functional ventricle (hypo plastic or absence of the right or left ventricle) is present in approximately half of asplenia cases and may be associated with bilateral right atrial appendage, bilateral trilobed lungs, bilateral eparterial bronchi, bilateral superior vena cava, TAPVC to a systemic vein, absent coronary sinus septum, common atrium, AVSD, DORV, or transposition of the great arteries (TGA) with bilateral or subaortic conus, and subvalvular or valvular pulmonary stenosis or atresia. ${ }^{[26]}$ Our case had trilobed left lung, absent spleen, centrally placed liver and malrotated intestines. Heart was normally located, but the left sided chambers were hypoplastic with atrial and ventricular septal defect (Figure- 3).

One of our cases had micrognathia, prominent occiput and absent thumb with associated club foot and micromelia which could be given a diagnosis of Otocephaly. Otocephaly is a rare, often lethal has familial anomaly characterized by microstomia, aglossia, agnathia and synotia ${ }^{[27]}$ with an incidence of less than 1 in 70,000 births ${ }^{[28]}$.

One of our cases was diagnosed to have Hypoplastic left heart syndrome (HLHS) which is a major lethal congenital anomaly reported to occur in $0.016-0.036 \%$ of all live births with a recurrence rate of $0.5 \%$. ${ }^{[29]}$ The aetiology of HLHS is not precisely known however autosomal recessive, autosomal dominant and polygenic inheritances have been suggested. ${ }^{[30]}$

\section{Conclusion}

Foetal and perinatal autopsy remains gold standard for diagnosing the cause of death despite the advent of higher technologies and helps in prenatal genetic counselling.

\section{References}

1. Cousens S, Blencowe H, Stanton C, Chou D, Ahmed S, Steinhardt L, et al. National, regional, and worldwide estimates of stillbirth rates in 2009 with trends since 1995: a systematic analysis. The Lancet 2011;377:1319-30.

2. Joseph R. Ophoven. Perinatal, fetal, and embryonic autopsy. In: Gilbert-Barness, editor. Potter's Pathology of the Fetus, Infant and Child, 2nd ed. Philadelphia: Mosby Elsevier; 2007. p. 695-08.

3. Boyd PA, Tondi F, Hicks NR, Chamberlain PF. Autopsy after termination of pregnancy for fetal anomaly: retrospective cohort study. bmj 2004;328:137.

4. Johns N, Al $\square$ Salti W, Cox P, Kilby MD. A comparative study of prenatal ultrasound findings and post $\square$ mortem examination in a tertiary referral centre. Prenatal diagnosis 2004;24:339-46.

5. Akgun H, Basbug M, Ozgun MT, Canoz O, Tokat F, Murat $\mathrm{N}$, et al. Correlation between prenatal ultrasound and fetal autopsy findings in fetal anomalies terminated in the second trimester. Prenatal diagnosis 2007;27:457-62.

6. Sailer DN, Lesser KB, Harrel U, Rogers BB, Oyer CE. The clinical utility of the perinatal autopsy. Jama 1995;273:663-5.

7. Gardosi J, Kady SM, McGeown P, Francis A, Tonks A. Classification of stillbirth by relevant condition at death (ReCoDe): population based cohort study. Bmj 2005;331:1113-7.

8. Vergani P, Cozzolino S, Pozzi E, Cuttin MS, Greco M, Ornaghi S, et al. Identifying the causes of stillbirth: a comparison of four classification systems. American journal of obstetrics and gynecology 2008;199:319-e1.

9. World Health Organization. The WHO Application of ICD-10 to deaths during pregnancy, childbirth and the puerperium. In: The WHO Application of ICD-10 to deaths during pregnancy, childbirth and puerperium: ICD-MM. Geneva: WHO; 2012. p. 7.

10. Sankar VH, Phadke SR. Clinical utility of fetal autopsy and comparison with prenatal ultrasound findings. Journal of Perinatology 2006;26:224.

11. Joshi VV, Bhakoo ON, Gopalan S, Gupta AN. Primary causes of perinatal mortality-autopsy study of 134 cases. Indian Journal of Medical Research 1979;69:963-71.

12. Pradhan R, Mondal S, Adhya S, Raychaudhuri G. Perinatal autopsy: A study from India. Journal of Indian Academy of Forensic Medicine 2013;35:10-3.

13. Kaiser L, Vizer M, Arany A, Veszprémi B. Correlation of prenatal clinical findings with those observed in fetal autopsies: pathological approach. Prenatal diagnosis 2000;20:970-5.

14. Grover N. Congenital malformations in Shimla. The Indian Journal of Pediatrics 2000;67:249-51.

15. Tomatır AG, Demirhan H, Sorkun HC, Köksal A, Özerdem F, Cilengir N. Major congenital anomalies: a five-year retrospective regional study in Turkey. Genetics and Molecular Research 2009;8:19-27.

16. Mitchell SE, Reidy K, Costa FD, Palma-Dias R, Cade TJ, Umstad MP. Congenital Malformations Associated With a 
Single Umbilical Artery in Twin Pregnancies. Twin Research and Human Genetics 2015;18:595-600.

17. Gillim DL, Hendricks CH. Holoacardius: review of the literature and case report. Obstetrics \& Gynecology $1953 ; 2: 647-53$

18. Levi CS, Lyons EA, Martel MJ. Sonography of multifetal pregnancy. Diagnostic ultrasound. 2005;2:1207-9.

19. Hoyme HE, Higginbottom MC, Jones KL. Vascular etiology of disruptive structural defects in monozygotic twins. Pediatrics 1981;67:288-91.

20. Steffensen TS, Gilbert-Barness E, Spellacy W, Quintero RA. Placental pathology in trap sequence: clinical and pathogenetic implications. Fetal and pediatric pathology 2008;27:13-29.

21. Hall JG. Pena $\square$ Shokeir phenotype (fetal akinesia deformation sequence) revisited. Birth Defects Research Part A. Clinical and Molecular Teratology 2009;85:677-94.

22. Vogt J, Morgan NV, Marton T, Maxwell S, Harrison BJ, Beeson D, et al. Germline mutation in DOK7 associated with fetal akinesia deformation sequence. Journal of medical genetics 2009;46:338-40.
23. Moessinger AC. Fetal akinesia deformation sequence: an animal model. Pediatrics 1983;72:857-63.

24. Rubin LG, Schaffner W. Care of the asplenic patient. New England Journal of Medicine 2014;371:349-56.

25. Shiraishi I, Ichikawa H. Human heterotaxy syndrome. Circulation Journal 2012;76:2066-75.

26. Burton EC, Olson M, Rooper L. Defects in laterality with emphasis on heterotaxy syndromes with asplenia and polysplenia: an autopsy case series at a single institution. Pediatric and Developmental Pathology 2014;17:250-64.

27. Pauli RM, Patterson JC, Arya S, Gilbert EF. Familial agnathia- holoprosencephaly. American Journal Medicine Genetics. 1983;14:677-98

28. Faye-Peterson O, David E, Rangwala N, et al. Otocephaly: Report of five new cases and a literature review. Fetal Pediatr Pathol. 2006; 25: 277-96.

29. Morris CD, Outcalt J, Menashe VD. Hyplastic left heart syndrome: natural history in a geographically defined population. Pediatrics 1990, 85(6):977- 983.

30. Grobman W, Pergament E. Isolated hypoplastic left heart syndrome in three siblings. Obstet Gynecol 1996;88:673-5.

*Corresponding author:

Dr. Sharanabasav M Choukimath, Postal Address: Assistant Professor, Department of Pathology, Karnataka Institute of Medical Sciences,

Hubballi, Karnataka - $\mathbf{5 8 0 0 2 2}$

Phone: +91 9448316911

Email: choukimathsm@gmail.com

Financial or other Competing Interests: None. 